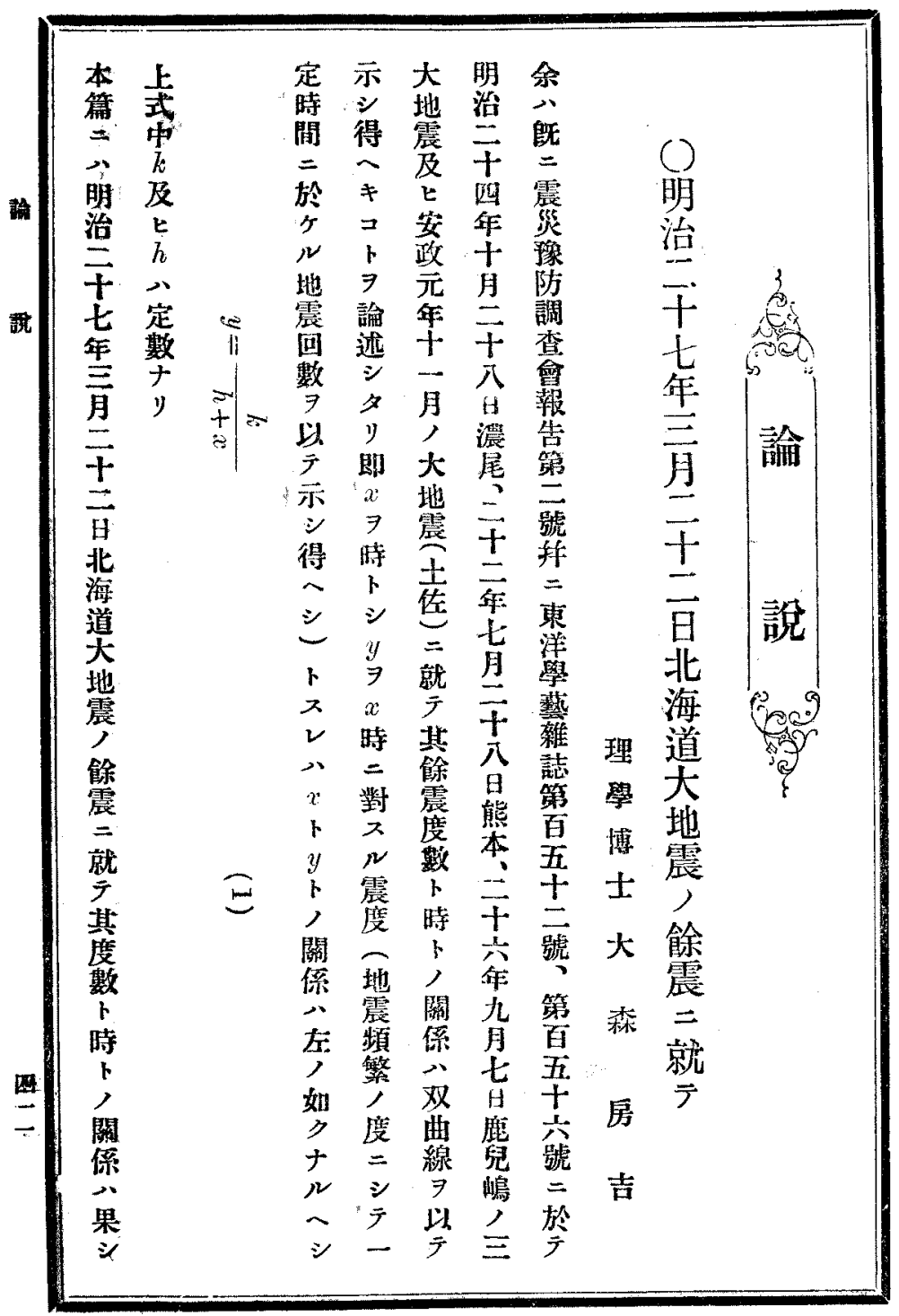




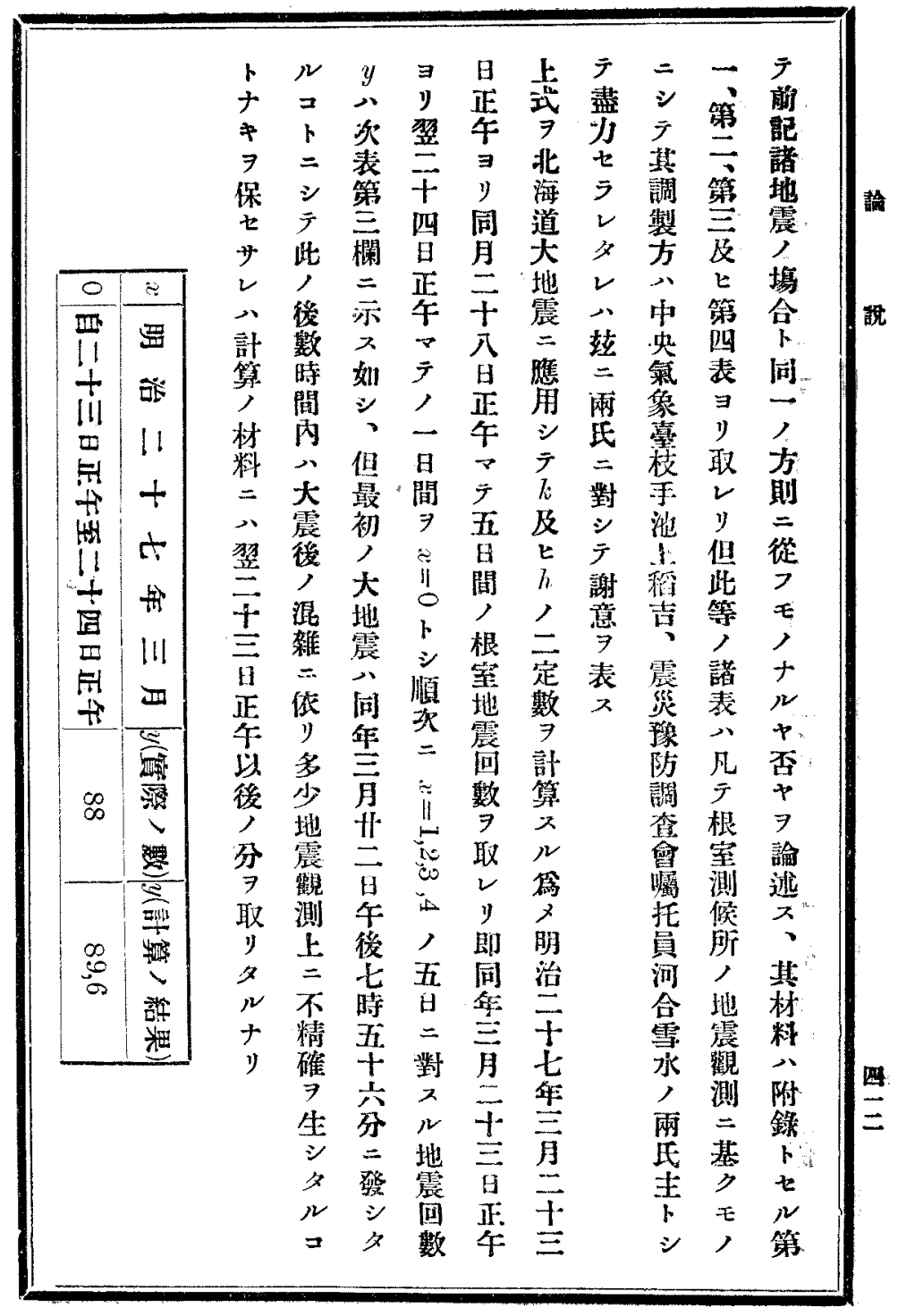




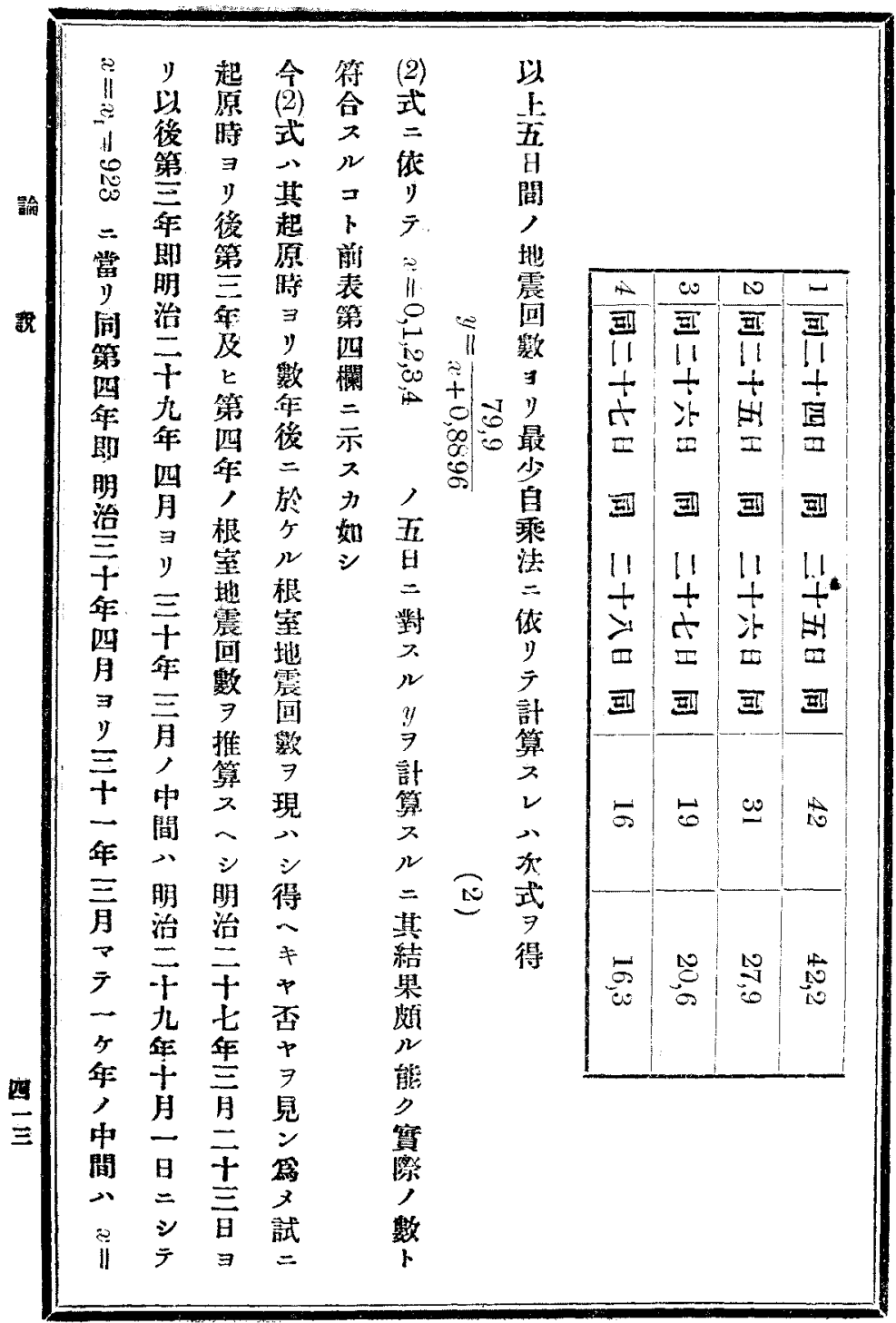




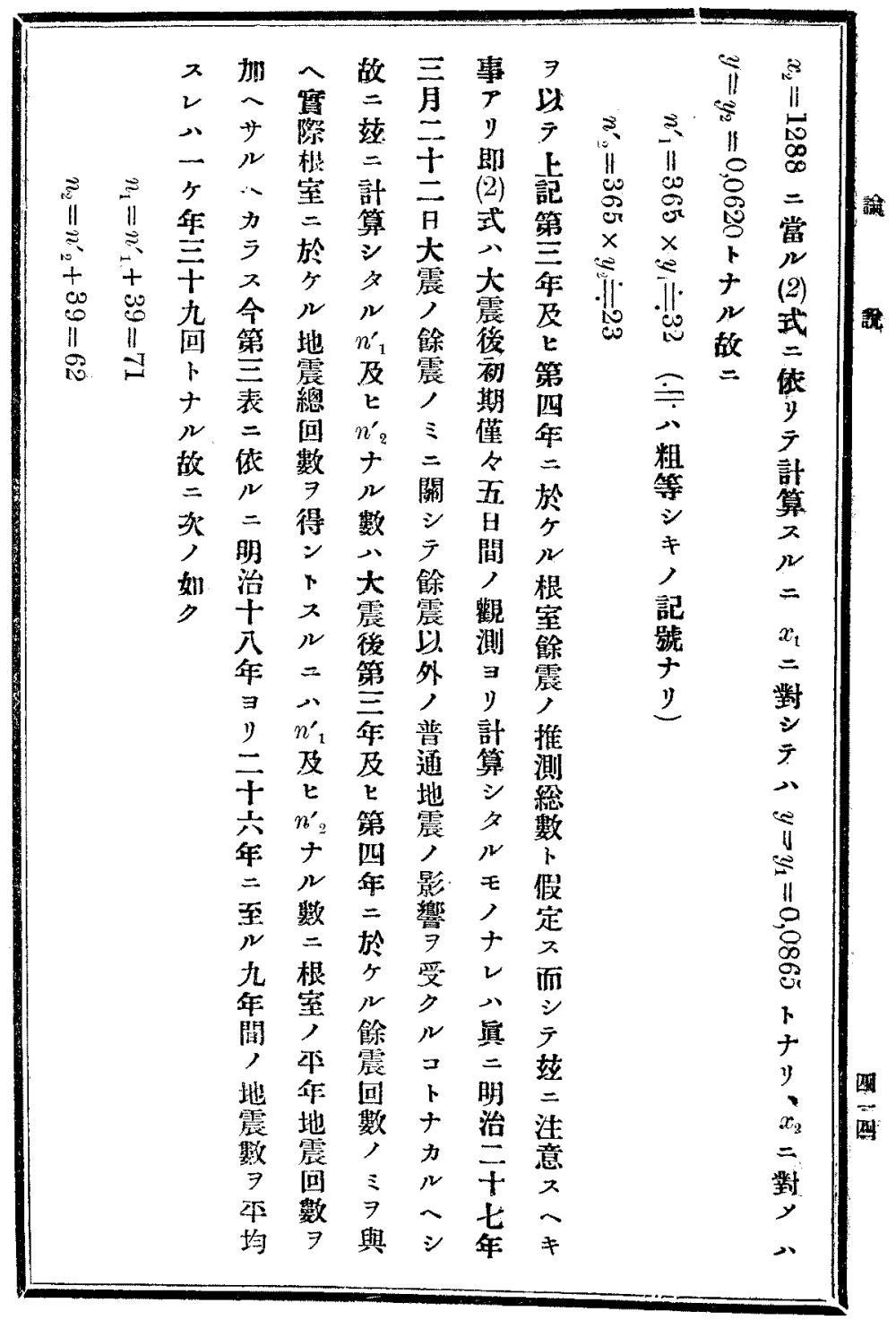




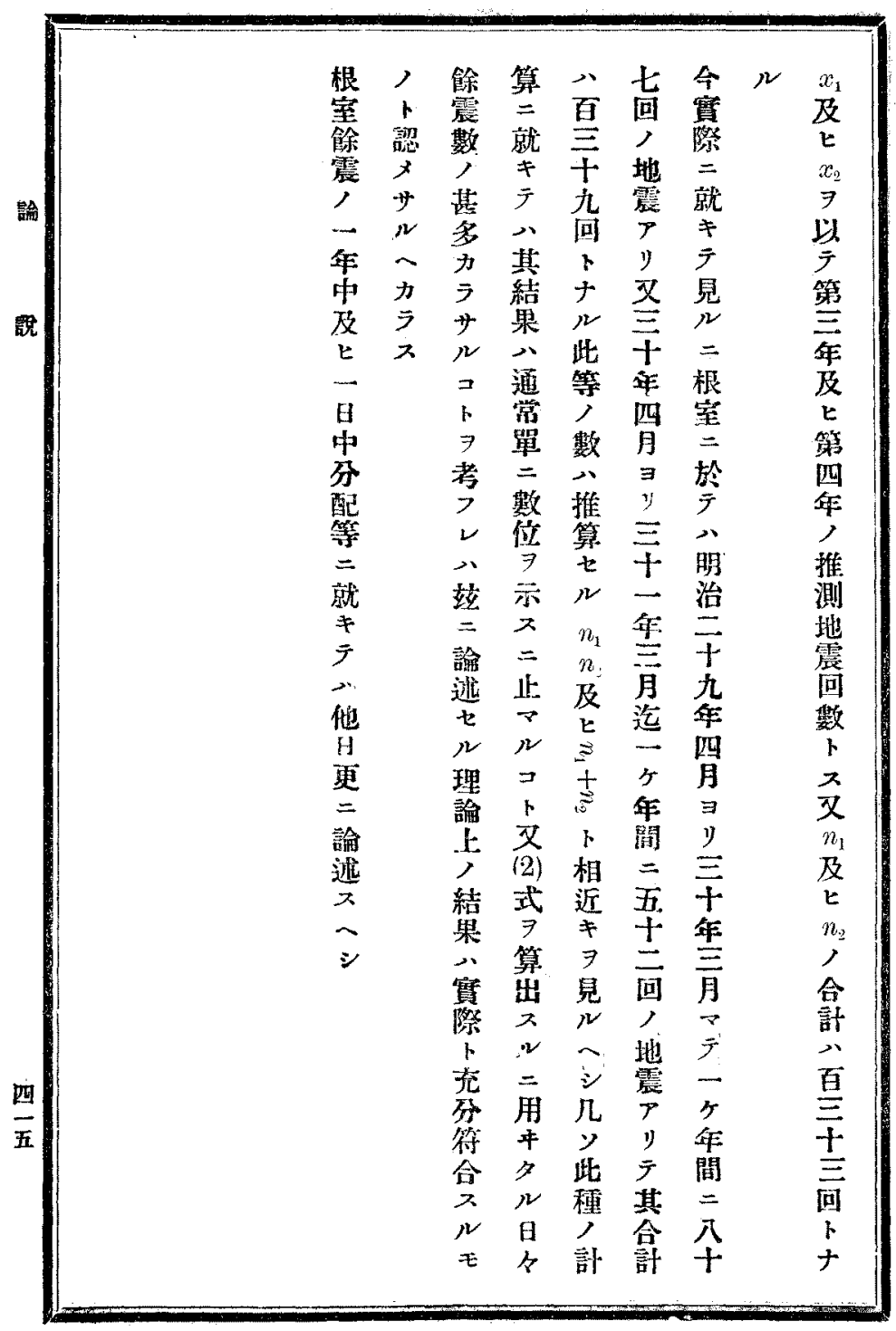




\section{第一表 根室每一㭙間地震回數}

(明治二十七年三月二十二日ョ同三十一日二至ル)

\begin{tabular}{|c|c|c|c|c|c|c|c|c|c|c|}
\hline 時間 & 22 & 23 & 24 & 25 & 26 & 27 & 28 & 29 & 30 & 31 \\
\hline 午前 $0-1$ & & & 7 & 0 & 2 & & 0 & 0 & 0 & \\
\hline $\begin{array}{l}1-1 \\
1-2\end{array}$ & & 4 & 1. & 1 & 1 & 0 & 0 & 0 & 0 & 0 \\
\hline $2-3$ & & 4 & 2 & 1 & 0 & & & 0 & 0 & 1 \\
\hline $3-4$ & & 12 & 1 & 1 & 2 & 0 & 1 & 0 & 0 & 1 \\
\hline $4--5$ & & 15 & 0 & 2 & 3 & 1 & 1 & 0 & 0 & 0 \\
\hline $5-6$ & & 10 & 4 & 2 & 1 & 0 & 3 & 0 & 0 & 0 \\
\hline $6-7$ & & 7 & 6 & 2 & 1 & 1 & 0 & 0 & 1 & 0 \\
\hline $7-8$ & & 4 & 4 & 3 & 1 & 2 & 4 & 0 & 1 & 0 \\
\hline $8-9$ & & & 2 & $I$ & 1 & & & 0 & 0 & 1 \\
\hline $9-10$ & & 2 & 3 & 2 & 1 & 0 & 0 & 0 & 0 & () \\
\hline $10-11$ & & 1 & 2 & 2 & 1 & 0 & 0 & 1 & 0 & 0 \\
\hline $11-12$ & & 8 & 0 & 2 & 1 & 1 & & 0 & 0 & 0 \\
\hline 午後 0 時-1 & & 1 & 3 & 7 & $?$ & & & 7 & 0 & \\
\hline $1-2$ & & 4 & 1 & 2 & 0 & 0 & 0 & 0 & 0 & 0 \\
\hline $2-3$ & & 3 & 0 & 3 & 0 & 0 & 0 & 0 & 0 & 1 \\
\hline $3-4$ & & 7 & 2 & 1 & 2 & 0 & 0 & 0 & 0 & \\
\hline $4-5$ & & 3 & 2 & 2 & 1 & 0 & 0 & 0 & 0 & 1 \\
\hline $5-6$ & & 2 & 3 & 1 & 1 & 1 & 0 & I & 0 & \\
\hline $6-7$ & & 5 & 2 & 1 & 1 & 0 & 0 & 0 & 2 & 1 \\
\hline $7-8$ & 1 & 8 & 2 & 2 & 1 & 0 & 1 & 0 & 0 & 0 \\
\hline $8-9$ & 16 & 4 & 1 & 0 & 2 & 2 & 0 & 0 & 0 & \\
\hline $9-10$ & 13 & 5 & 6 & 2 & 0 & 2 & 0 & 0 & 0 & 0 \\
\hline $10-11$ & 7 & 1 & 0 & 0 & 1 & 0 & 0 & 0 & 0 & 0 \\
\hline $11-12$ & 13 & 4 & 1 & 1 & 1 & 1 & 0 & 0 & 0 & 1 \\
\hline 合計 & 50 & 136 & 55 & 35 & 27 & 13 & 11 & 3 & 4 & 8 \\
\hline
\end{tabular}


第二踒 根室每日地震回數

(明治二十七华三月二十二日ョり同年十二月三十一日二至ル)

\begin{tabular}{|c|c|c|c|c|c|c|c|c|c|c|}
\hline 百 月 & $\equiv$ & 四 & 五 & 宍 & 七 & 八 & 九 & + & + & $+二$ \\
\hline 1 & & 4 & 2 & 3 & 1 & 0 & 2 & 0 & 0 & 0 \\
\hline 2 & & 4 & 4 & 2 & 3 & 1 & 3 & 2 & 0 & 2 \\
\hline 3 & & 3 & 0 & 0 & 0 & 1 & 0 & 1 & 0 & 0 \\
\hline 4 & & 8 & 2 & 0 & 0 & 2 & 0 & 3 & 0 & 3 \\
\hline 5 & & 5 & 1 & 1 & 1 & 0 & 3 & 1 & 1 & 0 \\
\hline $\begin{array}{l}6 \\
7\end{array}$ & & $\begin{array}{l}4 \\
7\end{array}$ & 2 & 1 & 0 & $\begin{array}{l}0 \\
0\end{array}$ & 1 & 2 & 0 & 0 \\
\hline 8 & & 2 & 1 & 2 & 2 & 0 & 3 & I & 2 & $\begin{array}{l}1 \\
\mathrm{I}\end{array}$ \\
\hline 9 & & 4 & $I$ & 3 & 0 & 0 & 1 & 1 & 0 & 0 \\
\hline 10 & & 6 & 5 & 3 & 0 & 2 & 1 & 0 & 0 & 0 \\
\hline 11 & & 11 & 0 & 1 & 0 & I & 0 & 0 & 0 & 0 \\
\hline $\begin{array}{l}12 \\
13\end{array}$ & & 8 & $\begin{array}{l}3 \\
0\end{array}$ & $\begin{array}{l}3 \\
0 \\
0\end{array}$ & 2 & $\begin{array}{l}1 \\
0\end{array}$ & $\begin{array}{l}0 \\
0\end{array}$ & 1 & $\begin{array}{l}0 \\
0\end{array}$ & 0 \\
\hline 14 & & 2 & 1 & 1 & 1 & 0 & 1 & 1 & 2 & $\begin{array}{l}0 \\
0\end{array}$ \\
\hline 15 & & 3 & 3 & 0 & 0 & 0 & 0 & 1 & 1 & 0 \\
\hline 16 & & 2 & 1 & 2 & 0 & 0 & 1 & 1 & 0 & 3 \\
\hline 17 & & 1 & 3 & 0 & 0 & 0 & 0 & 2 & 1 & I \\
\hline 18 & & 3 & 0 & 0 & 1 & 2 & 1 & I & I & 0 \\
\hline 19 & & 2 & 3 & 2 & 1 & 1 & 1 & 2 & 1 & 1 \\
\hline 20 & & 2 & 1 & 0 & 3 & 0 & 0 & 0 & 1 & 0 \\
\hline 21 & 50 & 2 & 1 & 1 & 3 & 0 & 1 & 1 & 1 & 0 \\
\hline $\begin{array}{l}22 \\
23\end{array}$ & $\begin{array}{c}50 \\
136\end{array}$ & $\begin{array}{l}1 \\
5\end{array}$ & $\begin{array}{l}6 \\
0\end{array}$ & $\begin{array}{l}1 \\
0\end{array}$ & $\begin{array}{l}0 \\
0\end{array}$ & $\begin{array}{l}0 \\
0\end{array}$ & $\begin{array}{l}0 \\
0\end{array}$ & 2 & $\begin{array}{l}1 \\
0\end{array}$ & $\begin{array}{l}0 \\
0\end{array}$ \\
\hline 24 & 55 & 3 & 2 & 0 & 1 & 0 & 0 & 3 & 0 & 0 \\
\hline 2.5 & 3.5 & 3 & 0 & 1 & 0 & 2 & 1 & 0 & 0 & 0 \\
\hline 26 & 27 & 0 & 3 & 2 & 0 & 0 & I & 0 & & 0 \\
\hline 27 & 13 & 3 & 0 & 1 & 1 & 1 & $\begin{array}{l}0 \\
0\end{array}$ & 0 & 2 & $\begin{array}{l}0 \\
0\end{array}$ \\
\hline 28 & $\begin{array}{c}11 \\
3\end{array}$ & $\begin{array}{l}2 \\
4\end{array}$ & $\begin{array}{l}0 \\
0\end{array}$ & 4 & $\begin{array}{l}1 \\
0\end{array}$ & $\begin{array}{l}3 \\
0\end{array}$ & 1 & $\begin{array}{l}0 \\
1\end{array}$ & $\begin{array}{l}1 \\
1\end{array}$ & 0 \\
\hline $\begin{array}{l}29 \\
30\end{array}$ & $\begin{array}{l}3 \\
4\end{array}$ & $\begin{array}{l}4 \\
1\end{array}$ & 0 & 3 & $\mathrm{I}$ & 3 & 0 & 1 & 0 & 0 \\
\hline $\begin{array}{l}31 \\
31\end{array}$ & 8 & - & 0 & - & 0 & 0 & - & j & - & 0 \\
\hline 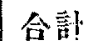 & 342 & 111 & 45 & 39 & 24 & 20 & 23 & 30. & 17 & 12 \\
\hline
\end{tabular}




\section{第三表 根室每月地震回數}

(明治十八年ヨり同二十宍年二至ハ)

\begin{tabular}{|c|c|c|c|c|c|c|c|c|c|c|c|c|}
\hline 年 月 & $\rightarrow$ & $=$ & $\equiv$ & 四 & 五 & 点 & 七 & 八 & 九 & - & & $+=$ \\
\hline $\begin{array}{c}\text { 明治十八年 } \\
\text { 士九 } \\
\text { 三十 } \\
\text { 三十二 } \\
\text { 三十三 } \\
\text { 三十三 } \\
\text { 三十四 } \\
\text { 三十五 } \\
\text { 三十六 }\end{array}$ & $\begin{array}{l}0 \\
2 \\
2 \\
0 \\
6 \\
3 \\
2 \\
5 \\
3\end{array}$ & $\begin{array}{l}0 \\
5 \\
2 \\
3 \\
3 \\
3 \\
3 \\
1 \\
1\end{array}$ & $\begin{array}{l}3 \\
4 \\
0 \\
4 \\
1 \\
3 \\
7 \\
1 \\
2\end{array}$ & $\begin{array}{l}1 \\
3 \\
2 \\
0 \\
3 \\
6 \\
3 \\
2 \\
2\end{array}$ & $\begin{array}{l}1 \\
3 \\
7 \\
1 \\
7 \\
7 \\
7 \\
2 \\
3 \\
4 \\
4\end{array}$ & \begin{tabular}{c|}
4 \\
3 \\
2 \\
2 \\
2 \\
6 \\
3 \\
3 \\
0 \\
12
\end{tabular} & $\begin{array}{l}5 \\
2 \\
5 \\
1 \\
7 \\
0 \\
3 \\
2 \\
4\end{array}$ & $\begin{array}{l}1 \\
4 \\
5 \\
2 \\
3 \\
3 \\
3 \\
1 \\
5\end{array}$ & $\begin{array}{l}4 \\
4 \\
1 \\
1 \\
6 \\
4 \\
2 \\
4 \\
5\end{array}$ & $\begin{array}{l}7 \\
5 \\
1 \\
2 \\
3 \\
2 \\
4 \\
5 \\
4\end{array}$ & $\begin{array}{c}6 \\
2 \\
3 \\
1 \\
3 \\
10 \\
2 \\
3 \\
4\end{array}$ & $\begin{array}{c}1 \\
6 \\
3 \\
1 \\
4 \\
7 \\
11 \\
3 \\
2\end{array}$ \\
\hline 合 計 & 23 & 21 & 2.5 & 22 & 35 & 34 & 29 & 27 & 31 & 33 & 34 & 38 \\
\hline
\end{tabular}

\section{第四表 根室每月地震回數}

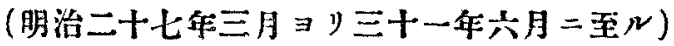

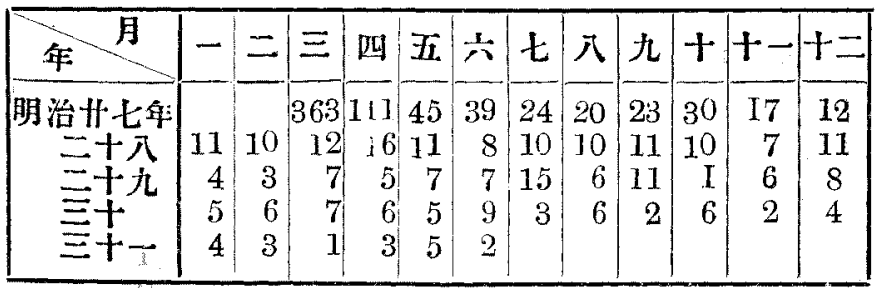

